\title{
Predictors of suicidal behaviour in 36,304 individuals sickness absent due to stress-related mental disorders - a Swedish register linkage cohort study
}

\author{
Kazi Ishtiak-Ahmed ${ }^{1,2}$, Aleksander Perski ${ }^{3}$ and Ellenor Mittendorfer-Rutz ${ }^{1 *}$
}

\begin{abstract}
Background: Stress-related mental disorders (SRMD), which correspond to the diagnostic code F43 in the International Classification of Diseases, version 10, rank among the leading causes of sickness absence in several European countries. Despite the size of this health problem, research on risk factors for severe medical outcomes, like suicidal behavior, is lacking to date. The aim of this study was to investigate predictors of suicide attempt and suicide among sickness absentees with SRMD.

Methods: A cohort of 36,304 non-retired individuals, aged 16-64 years on 31.12.2004, with at least one sickness absence spell due to SRMD, initiated in 2005, was followed up with regard to suicide attempt (2006-2009) and suicide (2006-2008). Univariate and multivariate hazard ratios (HR) with 95\% confidence intervals (Cl) were estimated for a number of predictors.

Results: During the follow-up period, 266 individuals attempted suicide and 34 committed suicide. In the multivariate analyses, the following factors increased the risk of suicide attempt: $=<25$ years of age, low educational level, lone parenthood, $>1$ sickness absence spell, long duration of the first spell of sickness absence due to SRMD (> 180 days), $>4$ and $>8$ days of inpatient care due to somatic or mental diagnoses (2000-2005), and $>4$ and $>1$ outpatient visits due to somatic or mental diagnoses (2001-2005), respectively. Hazard ratios ranged from 1.4 to 4.2. Health care due to mental diagnoses and $>1$ spell of sickness absence regardless of diagnosis were predictive of suicide.
\end{abstract}

Conclusions: Several predictors related to socio-demographics, sickness absence and health-care consumption were identified as risk factors for suicidal behavior. Consideration of these risk factors is of both clinical and public health importance.

Keywords: Suicide attempt, Suicide, Stress-related mental disorders, Sickness absence

\section{Background}

Sickness absence due to stress-related mental disorders Sickness absence due to mental disorders, particularly stress-related mental disorders, has increased in a number of European countries over the last 20 years, and currently comprises one of the major diagnostic groups among all cases of sickness absence [1,2]. Stress-related mental disorders correspond to diagnostic code F43 in the

\footnotetext{
* Correspondence: ellenor.mittendorfer-rutz@ki.se

'Division of Insurance Medicine, Department of Clinical Neuroscience, Karolinska Institutet, Stockholm, Sweden

Full list of author information is available at the end of the article
}

International Classification of Diseases (ICD, version 10), and include reactions to severe stress and adjustment disorders [3]. Despite the considerable increase and the size of the problem, research on the most serious medical outcomes, like the suicidal behaviour of sickness absentees with mental disorders and particularly stress-related mental disorders (SRMD) [4,5], is very limited [6,7]. Recent cohort studies have reported an increased risk of suicide in individuals on sick leave due to mental disorders in general [6], and on sick leave due to SRMD specifically [7].

Identifying risk individuals in time in order to prevent suicidal behavior is of utmost clinical and public health

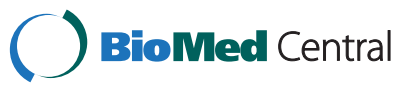


interest. Therefore, this study aimed to investigate the extent to which socio-demographic factors, as well as factors related to sickness absence and health-care consumption, predicted suicidal behavior in individuals sickness absent due to SRMD [8-11]. To the best of our knowledge, we are not aware of any previous study with a similar focus.

\section{Methods}

The study was designed as a prospective cohort study by linking Swedish register data. All people 16 to 64 yearsold on 31.12.2004 and registered in Sweden who initiated at least one sickness absence spell due to a stress-related mental disorder (SRMD) in $2005(\mathrm{~N}=38,870)$ comprised the study base. We excluded 2059 and 265 individuals who were on disability and old-age pension before 2005, respectively, and two further individuals who were erroneously coded as dead before 2005. Also, individuals with missing information on educational status $(\mathrm{N}=41)$, or on the length of the first sickness absence spell due to SRMD initiated in $2005(\mathrm{~N}=201)$, were excluded. This left 36,304 individuals (26,315 women and 9,989 men) to be included in the study.

The following register data sources were used for all the individuals in the study: 1) Statistics Sweden: Longitudinal Integration Database for Health Insurance and Labour Market Studies (LISA), which includes sociodemographic information on age, sex, country of birth, place of residence, family situation and educational status; 2) the National Board of Health and Welfare: (i) the National Patient Register, which includes information on dates and diagnoses for inpatient and outpatient care, (ii) the Cause of Death Register, with data on dates and causes of death; 3) the Social Insurance Agency (SIA): Micro-Data for Analyses of Social Insurance (MiDAS), with information on date, grade and diagnosis of sickness absence and disability pension. The linkages were based on the unique personal numbers (de-identified) of all residents in Sweden.

\section{The Swedish social insurance system}

All people above the age of 16, living in Sweden, with an income from work or unemployment benefit, who - due to disease or injury have a reduced work capacity - are covered by national sickness insurance and can receive sickness benefit [12]. After a first qualifying day, the employer is responsible for sick pay for the first 14 days of a sick leave spell; thereafter, sickness benefit is paid by the Social Insurance Agency. Self-employed people have more qualifying days, and they, as well as the unemployed, receive all sickness benefit from the Social Insurance Agency. A physician's certificate is required after seven days of self-certification. For this study, data on sick leave with benefit from the Social Insurance Agency were employed.

\section{Diagnostic criteria}

All diagnoses related to risk factors and outcomes were based on the corresponding codes of the International Classification of Diseases (ICD) in ICD 10. The definition of stress-related mental disorders in sickness absence spells was based on the corresponding ICD 10 Code F43.

\section{Measures of risk factors}

Baseline socio-demographic characteristics from the LISA database were measured at the end of 2004 and categorized as shown in Table 1. Variables on sickness absence relate to spells initiated in 2005. Number of sickness absence spells regardless of diagnosis was categorised as follows: 1, 2 and > 2 spells. The variable on diagnosisspecific sickness absence spells was categorised as follows: only spells due to mental disorders, one additional spell due to a somatic disorder, and multiple additional spells due to somatic disorders. Duration of the first sickness absence spell due to SRMD initiated in 2005 was grouped in five categories: 1-14, 15-90, 91-180, 181-365, and more than 365 days. The following covariates were dichotomized: having at least one full-time period (at least one day with $100 \%$ sickness absence) in the first sickness absence spell due to SRMD; having at least one part-time period in the first sickness absence spell due to SRMD, and whether or not individuals had any repeated sickness absence spells due to SRMD.

Categorisation of health care variables was based on the diagnosis-specific median number of days and number of visits in inpatient (2000-2005) and outpatient care (20012005) (four variables). The median length of hospital stays due to mental and somatic diagnoses were 8 and 4 days, respectively, while the median numbers of visits in outpatient care due to mental and somatic diagnoses were one and four, respectively.

\section{Measurement of outcome}

Individuals with inpatient care due to ICD-10 codes X60X84 were regarded as cases of suicide attempt. We considered only the first suicide attempt during the follow-up period. People with similar ICD codes in the Cause of Death register were considered as cases of suicide.

\section{Statistical analysis}

Cox proportional hazard regression models were applied after ensuring that the proportional hazard assumption was met. With regard to suicide attempt, individuals were followed from 01.01. 2006 to the date of inpatient care due to suicide attempt, death, emigration, or 31.12. 2009, whichever came first. With regard to suicide, follow-up was from 01.01. 2006 to the date of suicide, death by other causes than suicide, emigration, or 31.12. 2008, whichever came first. Hazard ratios for suicide attempt and suicide were estimated with 95\% confidence intervals. The multivariate 
Table 1 Descriptive statistics for individuals ( $N=36,304$ ) sickness absent due to stress-related mental disorders

\begin{tabular}{llll}
\hline Characteristics & N & $\%$ \\
\hline
\end{tabular}

Socio-demographic characteristics

Sex

Female

Male

Age (years)

$17-25$

26-35

$36-45$

46-55

$56-65$

Education (years)

0 to 9

10 to 12

Above 12

Country of birth

Sweden

Other Nordic countries

Other European countries

Outside Europe

Place of residence

Big cities

Medium size cities

small town

Family situation

Married/cohabiting without children ${ }^{\text {a }}$

Married/cohabiting with children ${ }^{\text {a }}$

Single people without children ${ }^{\text {a }}$

Single people with children ${ }^{a}$

Sickness absence characteristics ${ }^{b}$

Repeated spells

1 spell due to SRMD*

$>1$ spell due to SRMD*

Spells with mental/somatic diagnoses

Only spells with mental diagnoses

One additional spell with somatic diagnoses

Multiple spells with somatic diagnoses

Full-time ${ }^{c}$

No

Yes

Part-time $^{\mathrm{d}}$

No

Yes
34569

1735

32586

3330

$26315 \quad 72.5$

9989

1821

8216

11464

9138

5665

4362

18066

13876

31763

1313

2511

14017

12869

9418

4663

13955

11490

6196

95.2

4.8
Table 1 Descriptive statistics for individuals $(\mathrm{N}=36,304)$ sickness absent due to stress-related mental disorders (Continued)

\begin{tabular}{lrr}
\hline Duration (days) $^{\text {e }}$ & & \\
$1-14$ & 10157 & 28.0 \\
$15-90$ & 17370 & 47.8 \\
$91-180$ & 3742 & 10.3 \\
$181-365$ & 2469 & 6.8 \\
$>$ 365 & 2566 & 7.1 \\
Number of spells ${ }^{f}$ & & \\
1 spell & 30048 & 82.8 \\
2 spells & 5291 & 14.6 \\
$>$ 2 spells & 965 & 2.7
\end{tabular}

\section{Health care characteristics}

Hospital stay due to mental diagnoses (days) ${ }^{9}$

$\begin{array}{lrr}\text { No hospital stay } & 35036 & 96.5 \\ 1 \text { to } 8 & 663 & 1.8 \\ >8 & 605 & 1.7\end{array}$

Hospital stay due to somatic diagnoses (days) ${ }^{\mathrm{g}}$

$\begin{array}{lrr}\text { No hospital stay } & 25619 & 70.6 \\ 1 \text { to } 4 & 5797 & 16.0 \\ >4 & 4888 & 13.5\end{array}$

Outpatient care visits due to mental diagnoses ${ }^{9}$

$\begin{array}{lrr}\text { No visits } & 33013 & 90.9 \\ 1 & 1763 & 4.9 \\ >1 & 1528 & 4.2\end{array}$

Outpatient care visits due to somatic diagnoses ${ }^{9}$

No visits

$8806 \quad 24.3$

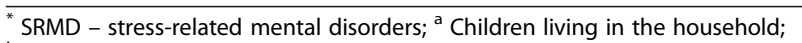
${ }^{\mathrm{b}}$ Sickness absence due to stress-related mental disorders; ${ }^{\mathrm{C}}$ Individual had at least one full-time period (at least one day with 100\% sickness absence) in the first sickness absence spell due to stress-related mental disorders; ${ }^{d}$ Individual had at least one part-time period (day) in the first sickness absence spell due to stress-related mental disorders; ${ }^{e}$ Duration of the first sickness absence spell due to stress-related mental disorders initiated in $2005 ;{ }^{f}$ Number of new sick leave spells initiated in 2005 regardless of diagnosis; ${ }^{9}$ Cut-offs are based on the diagnosis-specific median.

models included both significant predictors and significant confounders.

The partial likelihood ratio test was used to test for possible interactions between risk factors and to test the predictive value of variables in case of collinearity. Attributable proportions (APs) were estimated as follows: $\mathrm{AP}=(\mathrm{HR}-1) / \mathrm{HR}^{*} \mathrm{f}$, where $\mathrm{f}$ denotes the proportion exposed to the various risk factors in all who attempted or committed suicide [13]. All statistical analyses were performed using SPSS version 20. 


\section{Ethical considerations}

The study population was based on several linked public national registers, derived from three different authorities. Ethical vetting is always required when using register data in Sweden. The vetting is performed by regional ethical review boards, and a risk appraisal associated with the Law on Public Disclosure and Secrecy is performed by data owners. The ethical review boards can, however, waive the requirement to consult the data subjects (or, in case of minors/children, next of kin, carers or guardians) directly to obtain their informed consent, and will often do so if the research is supported by an ethical review board and the data have already been collected in some other context. This project was evaluated and approved, according to these standards, by the Regional Ethical Review Board of Karolinska Institutet, Stockholm, Sweden.

\section{Results}

In total, the 36,304 individuals contributed 143,836 personyears for suicide attempt and 108,520 person-years for suicide during the follow-up periods. The mean follow-up time was 3.96 years (standard deviation, SD: 0.33) for suicide attempt and 2.99 years (SD: 0.16) for suicide. With regard to suicide methods, out of the 34 suicides (0.1\%), 17 (50\%) were due to poisoning, and $12(35 \%)$ to hanging. A majority (94\%) of the $266(0.7 \%)$ suicide attempts were due to poisoning.

Table 1 presents descriptive statistics on the study population and on the suicide attempt/suicide cases with regard to socio-demographic characteristics, sickness absence spells and health care. In terms of proportions, the study population was female (72.5\%), aged between 36 and 45 years (31.6\%), had 10 to 12 years of education $(49.8 \%)$, was born in Sweden (87.5\%), lived in bigger cities (38.6\%), and was married/cohabiting with children living at home (38.4\%). With regard to the sickness absence characteristics, most of the individuals had only one sickness absence spell due to SRMD initiated in 2005 (82.8\%), had no additional sickness absence spells due to a somatic diagnosis (89.8\%), had at least one full-time sickness absence period in the first sickness absence spell due to SRMD (87.3\%), and 1590 days of sickness absence due to SRMD (47.8\%).

With regard to the health care characteristics, most of the individuals did not have any inpatient care due to either mental $(96.5 \%)$ or somatic diagnoses $(70.6 \%)$ between 2000 and 2005. At their first inpatient care stay due to a mental diagnosis in 2005, nearly half (43\%) of the individuals had SRMD as a main diagnosis; $14 \%$ had a mental and behavioural disorder due to use of alcohol (ICD-10 code F10), and 16\% a depressive episode (ICD-10 code F32) (data not shown).

The majority $(90.9 \%)$ of the study population did not have any health care visits in specialized outpatient care due to a mental diagnosis (2001-2005). At the first outpatient care visit due to a mental disorder in 2005, the main diagnosis was a stress-related mental disorder in $50 \%$ of cases, while $16 \%$ and $13 \%$ of the individuals had a main diagnosis of a depressive episode and an anxiety disorder, respectively (data not shown). A considerable proportion of the individuals had made up to four health care visits $(44.7 \%)$, or more than four health care visits (31\%), due to somatic diagnoses (Table 1).

\section{Suicide attempt and risk factors}

Most of the covariates were found to be significantly associated with suicide attempt in univariate analyses; the exceptions were sex, country of birth, and place of residence (Table 2). In the final model, young people (17-25 yearsold) showed a two-fold increased risk of attempting suicide compared with people aged 36-45 years (Table 3). Age over 56 years was significantly protective. Further, low education (HR 2.43, 95\% CI 1.63-3.63) and being single with children living at home HR 1.40 (95\% CI 0.991.96) were predictive of suicide attempt (Table 3 ).

In the multivariate model, people who had taken more than 365 days of sick leave due to SRMD during the first spell initiated in 2005 showed more than twice the risk of suicide attempt of people who had only 1-14 days of sickness absence (Table 3). The related attributable proportion (AP) was $3.15 \%$. Individuals with more than two sickness absence spells initiated in 2005, regardless of diagnosis, also showed a two-fold increased risk of suicide attempt compared with individuals with only one such spell (HR 2.02, 95\% CI 1.27-3.20; AP 6.40). All the other variables related to sickness absence spells were only significant in the univariate models.

The adjusted HR and AP were 4.15 (95\% CI 2.84-6.06) and 4.59, respectively, for individuals who had more than eight hospital days due to mental diagnoses during the years 2000 through 2005, compared with individuals who did not have any hospital stay (Table 3 ). The adjusted HR was increased three-fold, and the AP was $2.49 \%$, for people who had made more than one outpatient health care visit during the years 2001 through 2005 due to a mental diagnosis compared with individuals who did not make any such health care visits. Both inpatient and outpatient health care due to somatic diagnoses increased the suicide-attempt risk two-fold in the multivariate analyses (APs of $1.48 \%$ and $0.95 \%$, respectively).

\section{Suicide and risk factors}

Male gender, young age, being single without children living at home, having two sick leave spells regardless of diagnosis and diagnosis-specific inpatient and outpatient health care were found to be significantly associated with suicide in the univariate analyses (Table 4). In the multivariate model, having two sick leave spells, regardless of diagnosis, increased the risk of committing suicide more 
Table 2 Univariate hazard ratios (HR) and 95\% confidence intervals (Cl 95\%) for suicide attempt in people sickness absent due to stress-related mental disorders, SRMD $(\mathrm{N}=36,304)$

\begin{tabular}{|c|c|c|c|}
\hline Characteristics & $\mathrm{N}(\%)$ & HR & $\mathrm{Cl} 95 \%$ \\
\hline \multicolumn{4}{|l|}{ Socio-demographic characteristics } \\
\hline \multicolumn{4}{|l|}{ Sex } \\
\hline Male & $65(0.7)$ & 0.86 & $0.65-1.13$ \\
\hline Female & $201(0.8)$ & 1 & \\
\hline \multicolumn{4}{|l|}{ Age (years) } \\
\hline $17-25$ & $42(2.3)$ & 3.51 & $2.41-5.11$ \\
\hline $26-35$ & $75(0.9)$ & 1.38 & $1.00-1.90$ \\
\hline $36-45$ & $76(0.7)$ & 1 & \\
\hline $46-55$ & $60(0.7)$ & 0.99 & $0.71-1.39$ \\
\hline $56-65$ & $13(0.2)$ & 0.35 & $0.19-0.63$ \\
\hline \multicolumn{4}{|l|}{ Education (years) } \\
\hline 0 to 9 & $55(1.3)$ & 3.60 & $2.45-5.28$ \\
\hline 10 to 12 & $162(0.9)$ & 2.55 & $1.85-3.51$ \\
\hline Above 12 & $49(0.4)$ & 1 & \\
\hline \multicolumn{4}{|l|}{ Country of birth } \\
\hline Sweden & $228(0.7)$ & 1 & \\
\hline Other Nordic countries & $14(1.1)$ & 1.50 & $0.88-2.58$ \\
\hline Other European countries & $<4(0.3)$ & 0.39 & $0.10-1.57$ \\
\hline Outside Europe & $22(0.9)$ & 1.23 & $0.79-1.90$ \\
\hline \multicolumn{4}{|l|}{ Residence } \\
\hline Big cities & $105(0.7)$ & 1 & \\
\hline Medium sized cities & $89(0.7)$ & 0.92 & $0.70-1.22$ \\
\hline Small town & $72(0.8)$ & 1.02 & $0.76-1.38$ \\
\hline \multicolumn{4}{|l|}{ Family sitation } \\
\hline Married/cohabiting with children ${ }^{a}$ & $17(0.4)$ & 1 & \\
\hline Married/cohabiting without children ${ }^{a}$ & $76(0.5)$ & 0.67 & $0.40-1.14$ \\
\hline Single people without children ${ }^{a}$ & $108(0.9)$ & 1.74 & $1.30-2.33$ \\
\hline Single people with children ${ }^{a}$ & $65(1.0)$ & 1.93 & $1.39-2.69$ \\
\hline
\end{tabular}

Sickness absence characteristics ${ }^{b}$

Repeated spells

1 spell due to SRMD*
$>1$ spell due to SRMD*

Spells with mental/somatic disorders

Only spells with mental disorders

One additional spell with somatic disorders

Full-time ${ }^{c}$

No

Part-time $^{d}$

No 


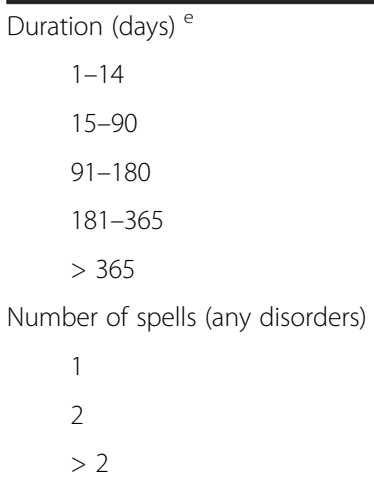

$$
\begin{array}{r}
48(0.5) \\
109(0.6) \\
38(1.0) \\
25(1.0) \\
46(1.8)
\end{array}
$$

\section{Health care characteristics}

Hospital stay due to mental disorders (days) ${ }^{9}$

$$
\begin{aligned}
& \text { No hospital stay } \\
& 1 \text { to } 8 \\
& >8
\end{aligned}
$$

Hospital stay due to somatic diagnoses (days) ${ }^{9}$

$$
\begin{aligned}
& \text { No hospital stay } \\
& 1 \text { to } 4 \\
& >4
\end{aligned}
$$

Outpatient care visits due to mental disorders ${ }^{9}$

$\begin{array}{lr}\text { No visits } & 161(0.5) \\ 1 & 33(1.9) \\ >1 & 72(4.7)\end{array}$

1
1.33
2.16
2.16
3.83

Outpatient care visits due to somatic disorders ${ }^{9}$

1 to 4

$$
164(1.5)
$$

${ }^{*}$ SRMD - stress-related mental disorders, ${ }^{a}$ Children living at home; ${ }^{b}$ Sickness absence due to stress-related mental disorders; ${ }^{c}$ Individual had at least one full-time period (at least one day with $100 \%$ sickness absence) in the first sickness absence spell due to stress-related mental disorders; ${ }^{d}$ Individual had at least one part-time period (day) in the first sickness absence spell due to stress-related mental disorders; ${ }^{e}$ Duration of the first sickness absence spell due to

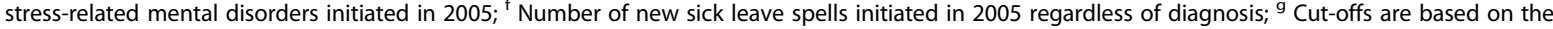
diagnosis-specific median.

than two-fold compared with having only one spell (HR 2.20, 95\% CI 1.07-4.55) (Table 5). The related AP was $1.69 \%$. People with previous inpatient care due to a mental diagnosis exceeding eight days had a three-fold increased risk of committing suicide compared with individuals without mental health care in the multivariate model (AP 4.80) (Table 5). The adjusted HRs for one and more than one outpatient care visit due to mental disorders were 3.69 (95\% CI 1.30-10.50) and 7.89 (95\% CI 3.34-18.67), respectively (Table 5); the APs were 5.02 and 2.29 , respectively.

\section{Discussion}

Young age, low education, lone parenthood, increasing numbers of days and spells of sickness absence, and inpatient and outpatient care due to mental and somatic diagnoses were predictive of suicide attempt in individuals who were sickness absent due to stress-related mental disorders. Previous and on-going inpatient and outpatient health care due to mental diagnoses and having two compared with only one spell of sickness absence predicted completed suicide.

\section{Methodology}

To the best of our knowledge, this study is the first to investigate predictors of suicide attempt and suicide among individuals with sickness absence due to stress-related mental disorders. The main strength of the study lies in the large data set that covers the whole Swedish population using register data of good quality [14-16]. Another strength is the prospective study design that includes four 
Table 3 Multivariate adjusted hazard ratios (HR) and $95 \%$ confidence intervals (Cl 95\%) for suicide attempt in people sickness absent due to stress-related mental disorders $(\mathrm{N}=36,304)$

\begin{tabular}{lll}
\hline Characteristics & HR $^{*}$ & $\mathrm{Cl} 95 \%$ \\
\hline
\end{tabular}

Socio-demographic characteristics

Age (years)

$17-25$

26-35

$36-45$

$46-55$

56-65

$1.31-2.98$

1.18

$0.86-1.64$

1

13

$0.80-1.60$

$0.24-0.82$

Education (years)

0 to 9

10 to 12

Above 12

Family situation

Married/cohabiting with children ${ }^{\text {a }}$

Married/cohabiting without children ${ }^{\mathrm{a}}$

Single people without children ${ }^{a}$

Single people with children ${ }^{a}$

Sickness absence characteristics ${ }^{b}$

Duration (days) ${ }^{c}$

$$
\begin{aligned}
& 1-14 \\
& 15-90 \\
& 91-180 \\
& 181-365 \\
& >365
\end{aligned}
$$

$1.63-3.63$

$1.45-2.78$

Number of spells (any disorders) ${ }^{d}$

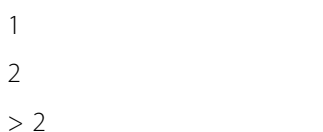

Health care characteristics

Hospital stay due to mental diagnoses (days) ${ }^{e}$

No hospital stay

\section{1 to 8}

$>8$

Hospital stay due to somatic diagnoses (days) ${ }^{\mathrm{e}}$

No hospital stay

1 to 4

$>4$

Outpatient care visits due to mental diagnoses (days) ${ }^{\mathrm{e}}$

No visits
1
$>1$

Table 3 Multivariate adjusted hazard ratios (HR) and 95\% confidence intervals ( $\mathrm{Cl}$ 95\%) for suicide attempt in people sickness absent due to stress-related mental disorders $(\mathbf{N}=\mathbf{3 6}, \mathbf{3 0 4})$ (Continued)

Outpatient care visits due to somatic diagnoses (days) ${ }^{e}$

$$
\text { No visits }
$$

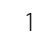

$1-4$

$>4$

$2.41 \quad 1.51-3.85$

* Analyses are adjusted for sex, age, education, type of family, duration of first sickness absence spell due to SRMD, number of spells due to SRMD, and all health care related predictors, ${ }^{a}$ Children living at home; ${ }^{\mathrm{b}}$ Sickness absence due to stress-related mental disorders; ${ }^{c}$ Duration of the first sickness absence spell due to stress-related mental disorders initiated in $2005 ;{ }^{d}$ Number of new sick leave spells initiated in 2005 regardless of diagnosis; ${ }^{~}$ Cut-offs are based on the diagnosis-specific median.

and three years of follow-up for suicide attempt and suicide, respectively, with practically no dropout. The study was also able to analyse a wide variety of risk factors related to socio-demographics, characteristics of sickness absence spells, and diagnosis-specific health care.

\section{Limitations}

The limitations of the study should also be mentioned, which include the limited power of the study with regard to the multivariate analysis of suicide as outcome. Another issue is the validity of sickness absence diagnoses, which is often discussed. A previous Swedish study, however, judged the validity of sickness absence diagnoses to be good [15]. In addition there is an on-going debate regarding whether and how stress-related mental disorders can be distinguished from depression; for example, post-traumatic stress disorders and depression often co-occur, and adjustment disorders in particular are difficult to distinguish from major depression [17]. Nevertheless, individuals sickness absent due to stress-related mental disorders differed considerably from the individuals absent due to depression found in a previous study, particularly with regard to suicide risk and degree of health-care consumption [7]. In addition, guidelines related to the diagnosis of stress-related mental disorders from the National Board of Health and Welfare in Sweden indicate clearly that if another disorder, e.g. depression, is present, depression should be used as the main diagnosis [18].

Since only the main diagnosis is recorded for any sickness absence spell in the Social Insurance Agency's register, we have missed individuals with a stress-related mental disorder as a secondary diagnosis. Also, we could not adjust for other mental and somatic diagnoses as comorbidities involved in the cases of sickness absence. Comorbid diagnoses are established predictors of suicidal behaviour [19]. Nevertheless, we could analyse the effect of inpatient and outpatient care due to a somatic or mental diagnosis as a measure of morbidity. 
Table 4 Univariate hazard ratios (HR) and 95\% confidence intervals (Cl 95\%) for suicide in people sickness absent due to stress-related mental disorders $(\mathrm{N}=36,304)$

Socio-demographic characteristics

Sex
Male
Female
Age (years)
$17-25$
26-35
36-45
46-55
$56-65$

Education (years)

$$
\begin{aligned}
& 0-9 \\
& 10-12
\end{aligned}
$$$$
>12
$$

Country of birth

$$
\text { Sweden }
$$

Other Nordic countries

Other European countries

Outside Europe

Place of residence

$$
\begin{aligned}
& \text { Big cities } \\
& \text { Medium size cities } \\
& \text { Small town }
\end{aligned}
$$

Family sitation

Married/cohabiting with children ${ }^{\text {a }}$

Married/cohabiting without children ${ }^{a}$

Single people without children ${ }^{\text {a }}$

Single people with children ${ }^{a}$

Sickness absence characteristics ${ }^{b}$

Repeated spells

$$
\begin{aligned}
& 1 \text { spell due to SRMD* } \\
& >1 \text { spell due to SRMD* }
\end{aligned}
$$

Spell with mental/somatic disorders

Only spells with mental disorders

One additional spell with somatic disorders

Multiple spells with somatic disorders

Full-time ${ }^{c}$

No

Yes

Part-time ${ }^{d}$

No

Yes

$$
\text { N (\%) }
$$

HR

Cl, $95 \%$

$$
\begin{array}{r}
16(0.16) \\
18(0.07) \\
6(0.33) \\
4(0.05) \\
11(0.10) \\
12(0.13) \\
<4(0.02)
\end{array}
$$

$<4(0.07)$

$18(0.10)$

13 (0.09)

29 (0.09)

$0(0.00)$

$0(0.00)$

$5(0.20)$

14 (0.10)

$12(0.09)$

$8(0.08)$

$<4(0.02)$

$8(0.06)$

19 (0.17)

$6(0.10)$

$4(0.12)$

$0(0.00)$

$0(0.00)$

34 (0.11)

21 (0.12)

$13(0.07)$
2.35

$1.20-4.61$

1

3.44

$1.27-9.29$

0.51

0.16-1.59

1.37

$0.60-3.10$

0.19

0.02-1.43

1.45

0.43-4.91

1.36

0.39-4.78

1

1

2.19

0.85-5.65

0.93

0.43-2.02

0.85

$0.36-2.03$

0.05-3.00

0.38

1.27-6.62

$0.59-4.87$

1.69

$0.59-4.87$

0.30-5.19

1.25

$0.46-3.72$

1.31

.

0.62

$0.31-1.24$ 


\begin{tabular}{|c|c|c|c|}
\hline \multicolumn{4}{|l|}{$\overline{\text { Duration (days) }^{\mathrm{e}}}$} \\
\hline $1-14$ & $7(0.07)$ & 1 & \\
\hline $15-90$ & $17(0.10)$ & 1.42 & $0.59-3.43$ \\
\hline $91-180$ & $4(0.11)$ & 1.56 & $0.45-5.30$ \\
\hline $181-365$ & $5(0.20)$ & 2.95 & $0.94-9.30$ \\
\hline$>365$ & $<4(0.04)$ & 0.57 & $0.07-4.60$ \\
\hline \multicolumn{4}{|c|}{ Number of spells (any disorders) ${ }^{f}$} \\
\hline 1 & $23(0.08)$ & 1 & \\
\hline 2 & $11(0.21)$ & 2.73 & $1.33-5.59$ \\
\hline$>2$ & $0(0.00)$ & - & - \\
\hline \multicolumn{4}{|c|}{ Health care characteristics } \\
\hline \multicolumn{4}{|c|}{ Hospital stay due to mental disorders (days) ${ }^{g}$} \\
\hline \multirow[t]{2}{*}{ No hospital stay } & $23(0.07)$ & 1 & \\
\hline & $5(0.75)$ & 11.61 & $4.41-30.53$ \\
\hline$>8$ & $6(0.99)$ & 15.23 & $6.20-37.41$ \\
\hline \multicolumn{4}{|c|}{ Hospital stay due to somatic disorders (days) ${ }^{g}$} \\
\hline No hospital stay & $20(0.08)$ & 1 & \\
\hline 1 to 4 & $5(0.09)$ & 1.11 & $0.42-2.95$ \\
\hline$>4$ & $9(0.18)$ & 2.37 & $1.08-5.20$ \\
\hline \multicolumn{4}{|c|}{ Outpatient care visits due to mental disorders ${ }^{g}$} \\
\hline No visits & $16(0.05)$ & 1 & \\
\hline 1 & $5(0.28)$ & 5.87 & $2.15-16.02$ \\
\hline$>1$ & $13(0.85)$ & 17.68 & $8.51-36.76$ \\
\hline \multicolumn{4}{|c|}{ Outpatient care visits due to somatic disorders ${ }^{9}$} \\
\hline No visits & $<4(0.02)$ & 1 & \\
\hline 1 to 4 & $15(0.09)$ & 4.07 & $0.93-17.80$ \\
\hline$>4$ & $17(0.15)$ & 6.66 & $1.54-28.83$ \\
\hline
\end{tabular}

In this study, we only considered cases of suicide attempt recorded in inpatient care. A study in Sweden has reported that approximately $47 \%$ of suicide attempters in the general population do not seek medical care after their suicide attempt [20]. We therefore expect that we only captured suicide attempts of greater medical severity.

\section{Socio-demographic factors}

We found that young age, low education and living alone with children were associated with an increased risk of suicide attempt, which is consistent with the findings of previous studies of the general population and of patients with mental disorders in other treatment settings [21]. Young people, in particular, are known to react to stressors and adverse life events more impulsively with suicidal behavior than people who are older [22] Awareness of these risk factors seems crucial to preventing suicide attempts in this patient group.

\section{Sickness absence characteristics}

The risk of attempting suicide was found to increase with increasing duration of sick leave and number of spells. Also, having 2 spells of sick leave, regardless of diagnosis, increased the risk of suicide more than two-fold. We have not been able to find any previous studies analysing the relation between frequency and duration of sickness absence spells and the risk of suicide attempt or suicide in individuals sickness absent due to stress-related mental disorders. Our findings are consistent with previous reports showing a 6-fold increased risk of suicide if there is 
Table 5 Multivariate Hazard ratios (HR) and 95\% Confidence Intervals (Cl 95\%) for suicide in people sickness absent due to stress-related mental disorders $(\mathrm{N}=36,304)$

\begin{tabular}{lrr}
\hline Characteristic & HR ${ }^{*}$ & Cl, 95\% \\
\hline Sickness absence characteristics $^{a}$ & & \\
Number of spells (any disorders) ${ }^{\text {b }}$ & & \\
1 & 1 & \\
2 & 2.20 & $1.07-4.55$
\end{tabular}

\section{Health care characteristics}

Hospital stay due to mental disorders (days) ${ }^{c}$

$\begin{array}{lrr}\text { No hospital stay } & 1 & \\ 1 \text { to } 8 & 3.47 & 1.22-9.92 \\ >8 & 3.66 & 1.33-10.07\end{array}$

Outpatient care visits due to mental diagnoses ${ }^{c}$

No visits

"HR adjusted for sex, age, family situation, number of sick spells (any disorders) and days of hospital stay and outpatient care visits due to mental diagnoses; ${ }^{\text {a }}$ Sickness absence due to stress-related mental diagnoses;

${ }^{\mathrm{b}}$ Number of new sick leave spells initiated in 2005 regardless of diagnosis;

c Cut-offs are based on the diagnosis-specific median.

more than one sick leave spell due to a psychiatric diagnosis after adjusting for age, gender, occupational grade, and sickness absence due to other diagnoses [6]. In addition, several studies have found sickness absence and increasing number of sickness absence days to be associated with suicide $[23,24]$. Our study is the first to show that sickness absence continues to be a risk factor even after controlling for inpatient and outpatient health care due to mental and somatic diagnoses.

Duration and number of spells of sick leave may not solely be measures of the recurrence, severity and chronicity of the disorder [25] underlying sickness absence, but might also reflect inadequacy of treatment and rehabilitation efforts [25]. Furthermore, increasing length of sickness absence might be associated with delayed help-seeking, and adverse health behaviours like alcohol consumption and social isolation [26], which in turn can increase the suicide risk [27,28]. Early rehabilitation, measures to improve the working environment and facilitate return-to-work, and also adequate treatment and follow-up of patients seem warranted in order to prevent suicidal behaviour. These findings have strong implications for primary health care, since the majority of cases of sickness absence are managed in primary health care [7].

\section{Inpatient and outpatient health care}

Long hospital stays and frequent outpatient care visits due to mental diagnoses were found to be strongly associated with suicidal behaviour among individuals on sick leave due to SRMD. Although length of inpatient care due to mental diagnoses per se has been linked to an increased suicide risk [10,11,29-31], we are not aware of any previous studies investigating the effect of diagnosisspecific health care on patients on sick leave due to SRMD. Our results show an increased risk of suicide attempt with increasing days and visits to inpatient and outpatient care due to somatic diagnoses. Possible explanations for these findings include the association of somatic disorders with suicidal behaviour, and also potentially under-diagnosed mental disorders in individuals seeking health care due to somatic complaints [19,32]. Several mechanisms are likely to link somatic disorders to suicidal behaviour, e.g. the pain associated with the somatic disorder, or the psychological strain associated with a lethal somatic diagnosis such as cancer [19,32]. Adequate treatment and thorough follow-up of patients on sick leave due to SRMD with a history of frequent health care contacts due to both mental and somatic disorders are therefore warranted for the purpose of preventing suicidal behaviour.

\section{Conclusions}

Young age, low education, lone parenthood, long and frequent sickness absence spells and inpatient and outpatient care due to somatic and mental diagnoses are predictive of suicide attempt in individuals sickness absent due to stress-related mental disorders. With regard to suicide completion, frequent sickness absence spells, and also inpatient and outpatient care due to mental disorders turned out to be risk factors. It is of public health and clinical importance to be aware of these risk factors when designing strategies to prevent suicidal behavior in individuals on sick leave due to stress-related mental disorders. These findings have particular importance in primary health care settings, where the vast majority of sickness certification due to stress-related mental disorders takes place.

\section{Competing interests}

The authors have no competing interests to declare.

\section{Authors' contributions}

EMR is responsible for the core idea and study design. KIA and EMR carried out the data analyses and drafted the manuscripts. EMR, KIA and AP contributed to successive drafts and agreed on the final version of the manuscript. All authors read and approved the final manuscript.

Acknowledgements

We thank Linnea Kjeldgård, statistician, for data management.

\section{Funding}

EMR is the recipient of the Assistant Professorship grant from the Swedish Research Council. The study was also funded by the Stockholm Stress Centre.

\section{Author details}

${ }^{1}$ Division of Insurance Medicine, Department of Clinical Neuroscience, Karolinska Institutet, Stockholm, Sweden. ${ }^{2}$ Department of Public Health Sciences, Karolinska Institutet, Stockholm, Sweden. ${ }^{3}$ Stockholm University, Stockholm Stress Centre, Stockholm, Sweden 
Received: 26 October 2012 Accepted: 14 May 2013

Published: 21 May 2013

\section{References}

1. Järvisalo J, Andersson B, Boedeker W, Houtman I (Eds): Mental disorders as a major challenge in prevention of work disability experiences in finland, germany, the netherlands and sweden. Helsinki: KELA, The Social Insurance Institution Finland. Social Security and Health Report 66; 2005.

2. Hensing G, Wahlstrom R: Chapter 7. Sickness absence and psychiatric disorders. Scand J Public Health Suppl [Review] 2004, 63:152-180.

3. WHO: The ICD classification of mental and behavioural disorders. Clinical descriptions and diagnostic guidelines. World Health Organization; 1997.

4. Clegg A: Occupational stress in nursing: a review of the literature. J Nurs Manag 2001, 9(2):101-106.

5. Ramirez AJ, Graham J, Richards MA, Cull A, Gregory WM: Mental health of hospital consultants: the effects of stress and satisfaction at work. Lancet 1996, 347(9003):724-728

6. Melchior M, Ferrie JE, Alexanderson K, Goldberg M, Kivimaki M, Singh-Manoux A, Vahtera J, Westerlund H, Zins M, Head J: Does sickness absence due to psychiatric disorder predict cause-specific mortality? a 16-year follow-up of the GAZEL occupational cohort study. Am J Epidemiol Research Support, N.I.H., Extramural Research Support, Non-U.S. Gov't 2010, 172(6):700-707.

7. Mittendorfer Rutz E, Kjeldgård L, Runeson B, Perski3 A, Melchior M, Head J, Alexanderson K: Sickness absence Due to specific mental diagnoses and All-cause and cause-specific mortality: a cohort study of 4.9 Million inhabitants of sweden. PLoS One 2012, 7(9):e45788. Epub 2012 Sep 25.

8. Qin P, Agerbo E, Mortensen PB: Suicide risk in relation to socioeconomic, demographic, psychiatric, and familial factors: a national register- based study of all suicides in denmark, 1981-1997. Am J Psychiatry 2003, 160(4):765-772.

9. Monnin J, Thiemard E, Vandel P, Nicolier M, Tio G, Courtet P, Bellivier F, Sechter D, Haffen E: Sociodemographic and psychopathological risk factors in repeated suicide attempts: gender differences in a prospective study. J Affect Disord 2011, 136:35-43.

10. Appleby L, Dennehy J, Thomas C, Faragher E, Lewis G: Aftercare and clinical characteristics of people with mental illness who commit suicide: a case-control study. Lancet 1999, 353:1397-1400.

11. Appleby L, Shaw J, Amos T, McDonnell R, Harris C, McCann K, Kiernan K, Davies S, Bickley H, Parsons R: Suicide within 12 months of contact with mental health services national clinical survey. BMJ 1999, 318(7193):1235-1239.

12. Försäkringskassan: Social insurance in figures. The Social Insurance Agency; 2011.

13. Mittendorfer-Rutz E, Rasmussen F, Wasserman D: Restricted fetal growth and adverse maternal psychosocial and socioeconomic conditions as risk factors for suicidal behaviour of offspring: a cohort study. Lancet 2004, 364(9440):1135-1140.

14. Ludvigsson JF, Andersson E, Ekbom A, Feychting M, Kim JL, Reuterwall C, Heurgren M, Olausson PO: External review and validation of the swedish national inpatient register. BMC Public Health 2011, 11:450.

15. Ljungdahl LO, Bjurulf $P$ : The accordance of diagnoses in a computerized sick-leave register with doctor's certificates and medical records. Scand J Soc Med 1991, 19(3):148-153.

16. Socialstyrelsen: The cause of death register. 2009. Available from: www.socialstyrelsen.se.

17. Casey P, Bailey S: Adjustment disorders: the state of the art World Psychiatry 2011, 10(1):11-18.

18. The National Board of Health and Welfare (Socialstyrelsen): Fatique syndrome, stress related psychiatric disorders (utmattningssyndrom stressrelaterad psykisk ohälsa). Stockholm: The National Board of Health and Welfare (Socialstyrelsen); 2003.

19. Stenager NE, Stenager E: Physical illness and suicidal behaviour. In The international handbook of suicide and attempted suicide. Edited by Hawton K, van Heeringen K. Wiley: Wiley; 2002:405-420.

20. Ramberg IL, Wasserman D: Prevalence of reported suicidal behaviour in the general population and mental health-care staff. Psychol Med 2000, 30(5):1189-1196.

21. Christopher $\mathrm{H}$ : Chapter 1. Suicide in the western world. In The international handbook of suicide and attempt suicide. Edited by Hawton $\mathrm{K}$, van Heeringen K. Wiley; 2002:9-28.

22. Hawton K, Saunders KE, O'Connor RC: Self-harm and suicide in adolescents. Lancet 2012, 379(9834):2373-2382.
23. Qin P: Gender differences in risk factors for suicide in Denmark. $\mathrm{Br} J$ Psychiatry 2000, 177(6):546-550.

24. Vahtera J: Sickness absence as a predictor of mortality among male and female employees. J Epidemiol Community Health 2004, 58(4):321-326.

25. Bultmann U, Rugulies R, Lund T, Christensen KB, Labriola M, Burr H: Depressive symptoms and the risk of long-term sickness absence: a prospective study among 4747 employees in denmark. Soc Psychiatry Psychiatr Epidemiol 2006, 41(11):875-880.

26. Vingard E, Alexanderson K, Norlund A: Chapter 9. Consequences of being on sick leave. Scand J Public Health Suppl [Review] 2004, 63:207-215.

27. Deborah L, Trout MA: The role of social isolation in suicide. Suicide Life Threat Behav 2010, 10:10-23.

28. Murphy G: Chapter 9. Psychiatric aspects of suicidal behaviour: substance abuse. In The international handbook of suicide and attempted suicide. Edited by Hawton K, van Heeringen K. Wiley; 2002:135-146.

29. Hunt IM, Kapur N, Webb R, Robinson J, Burns J, Shaw J, Appleby L: Suicide in recently discharged psychiatric patients: a case-control study. Psychol Med [Comparative Study Research Support, Non-U.S. Gov't] 2009, 39(3):443-449.

30. Lee $\mathrm{H}$, Lin $\mathrm{H}$ : Are psychiatrist characteristics associated with postdischarge suicide of schizophrenia patients? Schizophr Bull 2009 35(4):760-765.

31. Lawrence DM, Holman CD, Jablensky AV, Fuller SA: Suicide rates in psychiatric in-patients an application of record linkage to mental health research. Aust N Z J Public Health 1999, 23(5):468-470.

32. Scott KM, Hwang I, Chiu WT, Kessler RC, Sampson NA, Angermeyer M, Beautrais A, Borges G, Bruffaerts R, De Graaf R, Florescu S, Fukao A, Haro JM, Hu C, Kovess V, Levinson D, Posada-Villa J, Scocco P, Nock MK: Chronic physical conditions and their association with first onset of suicidal behavior in the world mental health surveys. Psychosom Med [Comparative Study Research Support, N.I.H., Extramural Research Support, Non-U.S. Gov't] 2010, 72(7):712-719.

doi:10.1186/1471-2458-13-492

Cite this article as: Ishtiak-Ahmed et al:: Predictors of suicidal behaviour in 36,304 individuals sickness absent due to stress-related mental disorders - a Swedish register linkage cohort study. BMC Public Health 2013 13:492.

\section{Submit your next manuscript to BioMed Central and take full advantage of:}

- Convenient online submission

- Thorough peer review

- No space constraints or color figure charges

- Immediate publication on acceptance

- Inclusion in PubMed, CAS, Scopus and Google Scholar

- Research which is freely available for redistribution 